Int. J. Electrochem. Sci., 15 (2020) 3869 - 3890

\title{
Mini review \\ Electrochemical Biosensors with Silver Nanoparticles as Signal Labels
}

\author{
Cai-Xia Yu ${ }^{1, *}$, Fan Xiong ${ }^{1}$ and Lei-Lei Liu ${ }^{2, *}$ \\ ${ }^{1}$ Henan Province of Key Laboratory of New Optoelectronic Functional Materials, College of \\ Chemistry and Chemical Engineering, Anyang Normal University, Anyang, Henan 455000, People's \\ Republic of China \\ ${ }^{2}$ School of Environment and Material Engineering, Yantai University, Yantai 264005, People's \\ Republic of China \\ *E-mail: yucaixiachem@163.com (C. X. Yu), liuleileimail@163.com (L. L. Liu)
}

doi: $10.20964 / 2020.05 .53$

Received: 6 Janaury 2020 / Accepted: 12 February 2020 / Published: 10 April 2020

The fabrication of electrochemical biosensors with high sensitivity and selectivity has attracted increasing attention during the past decades. Due to their excellent chemical and electrical properties, especially low-redox potential and highly characteristic solid-state $\mathrm{Ag} / \mathrm{AgCl}$ process, silver nanoparticles (AgNPs) have been extensively employed to design novel and efficient electrochemical sensing methods. Herein, we summarize the applications of AgNPs as electroactive labels in biosensors. This review aims to provide a snapshot of recent development of AgNPs-based electrochemical sensors and to illustrate their benefits for biological and biomedical applications.

Keywords: silver nanoparticles; signal amplification; electrochemical biosensors; silver deposition; biometallization

\section{FULL TEXT}

(C) 2020 The Authors. Published by ESG (www.electrochemsci.org). This article is an open access article distributed under the terms and conditions of the Creative Commons Attribution license (http://creativecommons.org/licenses/by/4.0/). 